MATEC Web of Conferences 13,03011 (2014)

DOI: 10.1051/matecconf/ 20141303011

(C) Owned by the authors, published by EDP Sciences, 2014

\title{
On-Line Condition Monitoring System for High Level Trip Water in Steam Boiler's Drum
}

Firas B. Ismail Alnaimi ${ }^{1,}$, Marwan A Ali ${ }^{1}$, Hussain H. Al-Kayiem ${ }^{2}$ and Khairul Salleh bin Mohamed Sahari ${ }^{1}$

${ }^{1}$ Department Of Mechanical Engineering, Universiti Tenaga Nasional, Jalan IKRAM-UNITEN, Kajang, 43000, Selangor, Malaysia

${ }^{2}$ Mechanical Engineering Department, University Teknologi Petronas, Bandar Seri Iskandar, 31750

Tronoh, Perak, Malaysia.

\begin{abstract}
This paper presents a monitoring technique using Artificial Neural Networks (ANN) with four different training algorithms for high level water in steam boiler's drum. Four Back-Propagations neural networks multidimensional minimization algorithms have been utilized. Real time data were recorded from power plant located in Malaysia. The developed relevant variables were selected based on a combination of theory, experience and execution phases of the model. The Root Mean Square (RMS) Error has been used to compare the results of one and two hidden layer (1HL), (2HL) ANN structures
\end{abstract}

\section{Introduction}

Intelligent systems for plant status monitoring are anticipatory synthesis of signal validation, diagnostics and alarm filtering techniques. In brief the aim of these systems is to provide the operator with an assessment of the status of the plant as a whole with strong supporting justifications for conclusions made [1,2]. Kim et al. [3] demonstrated the feasibility of a multi layer NN model coupled with a stacked generalization technique to the early recognition of San Onofre nuclear station operational transients. Gugiielmi et al. [4] have adopted a multilayer feed forward and Radial Basis Function Neural Network (RBFNN) tool to solve real system diagnostic problems. Simani and Fantuzzi [5] designed a two-stage fault detection and diagnostic system for input-output industrial gas turbine process sensors. Babar and Kushwaha [6] proposed operator support system software based on the ANN as a means to identify the undesired plant condition (initiating event). Bae et al. [7] designed a fault diagnostic system using an $\mathrm{NN}$ based on the pattern of principle variables which could represent the type and severity of failures. Romeo and Gareta [8] designed a set of NN monitoring methodologies to analyze the influence of fouling and slagging for a biomass boiler. Due to the complexity in analytical modeling and its long computation time, Rusinowski and Stanek [9] have presented an NN estimation model for a steam boiler. In this work, intelligent computational condition monitoring system specialized in steam boiler's drums associated with real time data has been presented. The main objective of this system is early detection of high level Scenario in steam boiler's drum by adopting of four back-propagation training algorithms.

\section{Real Data Preparation Scheme for Level Drum Monitoring}

The monitoring system preparation for complex real time data has high importance. However, no standard real data preparation framework for monitoring system has so far been suggested. In view of the importance of real data preparation, we proposed an intelligent real data scheme for coal-fired

\footnotetext{
a Firas@uniten.edu.my
}

This is an Open Access article distributed under the terms of the Creative Commons Attribution License 2.0, which permits unrestricted use, distribution, and reproduction in any medium, provided the original work is properly cited. 
power plant drum level monitoring system. The suggested real data preparation scheme consists of three inter-stages: 1) ANN data pre-analysis stage, where the real plant data are captured, identified and sampled. 2) ANN data pre-processing stage, where plant data are tested, checked and processed. In this stage some data are restricted or transformed to be utilized in the intelligent monitoring system. 3) Stage of ANN data post analysis, where some data are validated and recalculated. This suggested real plant data preparation framework is wider than almost all existing researches because they include only the second inter-stage. Our framework monitoring system preparation would fill the gap of the related works literature. In the following sub-sections, the three inter-stages of the proposed real plant data preparation scheme are described briefly.

\subsection{Inter-Stage One}

\subsubsection{Data Requirement Analysis}

Full understanding of the real plant data requirements in conjunction with the domain of the problem definitions and expected objectives is important. Domain experts help to provide insight of the underlying process so that some potential problems may be avoided. [10]. Recognizing the real data requirements helps to capture it from various resources.

\subsubsection{Data Acquisition}

This stage is important because the results will restrict subsequent Inter-phases. The required data was captured from the thermal power station control room. The real data related to the steam boiler drum which consists of 93 variables and was accumulated on the base of $1 \mathrm{~min}$ interval for a period of one month for that trip. Each one of 93 variables was saved in a file which consists of 5200 data points.

\subsection{Inter-Stage Two}

In this stage, the on-line plant data was pre-processed, in which 93 variables were reduced to 32 variables by adapting the plant operator experience. The mean values of sum of the variables which are provided by multi-sensors have been considered. The set of plant operation variables is shown in Table 1.

\subsection{Inter-Stage Three}

Steam boiler drum data were pre-rondam before subdivided into three different groups for ANN training phase. 60 percentage of acquired data were used for training, 15 percentage was used for validation phase and the rest were used for testing phase. Random process of the data was applied on every set.

Table 1. Variables of the Power Plant's Boiler

\begin{tabular}{|c|l|c|c|l|c|}
\hline Sym. & Description & Unit & Sym & Description & Sym \\
\hline V1 & Total combined Steam flow & $\mathrm{t} / \mathrm{h}$ & V17 & Boiler circulation pump1 pressure & bar \\
\hline V2 & Feed water flow & $\mathrm{t} / \mathrm{h}$ & V18 & Boiler circulation pump2 pressure & bar \\
\hline V3 & Boiler drum pressure & Barg & V19 & $\begin{array}{l}\text { Low temperature super heater left } \\
\text { wall outlet before super heater dryer }\end{array}$ & ${ }^{\circ} \mathrm{C}$ \\
\hline V4 & Super heater steam pressure & Barg & V20 & $\begin{array}{l}\text { Low temperature super heater right } \\
\text { wall outlet before super heater dryer }\end{array}$ & ${ }^{\circ} \mathrm{C}$ \\
\hline V5 & Super heater steam temperature & ${ }^{\circ} \mathrm{C}$ & V21 & $\begin{array}{l}\text { Low temperature super heater left } \\
\text { wall after super heater dryer }\end{array}$ & ${ }^{\circ} \mathrm{C}$ \\
\hline V6 & $\begin{array}{l}\text { High temperature Re-heater outlet } \\
\text { temperature }\end{array}$ & ${ }^{\circ} \mathrm{C}$ & V22 & $\begin{array}{l}\text { Low temperature super heater right } \\
\text { wall exchange metal temperature }\end{array}$ & ${ }^{\circ} \mathrm{C}$ \\
\hline V7 & $\begin{array}{l}\text { High temperature super heater } \\
\text { exchange metal temperature }\end{array}$ & ${ }^{\circ} \mathrm{C}$ & V23 & $\begin{array}{l}\text { Intermediate temperature }(\mathrm{B}) \text { super } \\
\text { heater exchange metal temperature }\end{array}$ & ${ }^{\circ} \mathrm{C}$ \\
\hline V8 & $\begin{array}{l}\text { Intermediate temperature (A) super } \\
\text { heater exchange metal temperature }\end{array}$ & ${ }^{\circ} \mathrm{C}$ & V24 & $\begin{array}{l}\text { Intermediate temperature super } \\
\text { heater outlet before super heater } \\
\text { dryer }\end{array}$ & ${ }^{\circ} \mathrm{C}$ \\
\hline V9 & High temperature super heater inlet & ${ }^{\circ} \mathrm{C}$ & V25 & Intermediate temperature super & ${ }^{\circ} \mathrm{C}$ \\
\hline
\end{tabular}


ICPER -2014

\begin{tabular}{|c|c|c|c|c|c|}
\hline & header metal temperature & & & $\begin{array}{l}\text { heater outlet header metal } \\
\text { temperature }\end{array}$ & \\
\hline V10 & $\begin{array}{l}\text { final super heater outlet } \\
\text { temperature }\end{array}$ & ${ }^{\circ} \mathrm{C}$ & V26 & $\begin{array}{l}\text { High temperature super heater outlet } \\
\text { header metal temperature }\end{array}$ & ${ }^{\circ} \mathrm{C}$ \\
\hline V11 & $\begin{array}{l}\text { super heater steam pressure } \\
\text { transmitter (control) }\end{array}$ & bar & V27 & $\begin{array}{l}\text { High temperature Re-heater outlet } \\
\text { steam pressure }\end{array}$ & bar \\
\hline V12 & Feed water valve station & $\mathrm{t} / \mathrm{h}$ & V28 & $\begin{array}{l}\text { Super-heated steam form } \\
\text { Intermediate temperatures outlet } \\
\text { pressure }\end{array}$ & bar \\
\hline V13 & Feed water control valve position & $\%$ & V29 & $\begin{array}{l}\text { Super heater water injection } \\
\text { compensated flow }\end{array}$ & $\mathrm{t} / \mathrm{h}$ \\
\hline V14 & Drum level corrected (control) & $\mathrm{mm}$ & V30 & Economizer inlet pressure & bar \\
\hline V15 & $\begin{array}{l}\text { Drum level compensated (from } \\
\text { protection) }\end{array}$ & $\mathrm{mm}$ & V31 & Economizer inlet temperature & ${ }^{\circ} \mathrm{C}$ \\
\hline V16 & Feed water flow transmitter & $\%$ & V32 & Economizer outlet temperature & ${ }^{\circ} \mathrm{C}$ \\
\hline
\end{tabular}

\section{Pure Intelligent Monitoring System Modelling}

The feed-forward Back-propagation Training Algorithm was used here. It has several modifications in accordance to multi-dimensional minimization algorithm in which it uses the minimizing error estimator. Thirty two ANN Inputs (steam boiler drum operation variables) are identified in the previous section. All ANN outputs corresponded to steam boiler drum high level trip except one output that corresponded to normal operation. The output values during training and validation phases of the pure intelligent monitoring system range from 0 to 1 . From this point forward, a decision process was formed to determine which value of an output should be significant in terms of the existence of fault. The final architecture has been achieved after investigating various ANN topologies that include one and two hidden layers which contain one to ten neurons in each hidden layer, three types of activation functions, and four types of multidimensional minimization training algorithms. The accuracy of the trained intelligent monitoring system for data application is validated by observing the root mean square error of $\mathrm{NN}$ outputs (high level trip indicator) from the data sets. This validation procedure has never been done in any developed pure intelligent monitoring system before. The training phase of the pure intelligent monitoring system was carried out using MATLAB codes.

\section{Results and Discussions}

Fifteen days' worth of data were obtained from Coal-Fired power plant steam boiler systems located in Malaysia to form the final training data set. The training set was based on 1,225 entries for each input of the artificial neural network with the time interval of 1 minute. The training phase contains two basic components. Firstly the initial training phase to determine the best group of architecture and algorithm. This was completed by train several candidate network topologies (both 1-HL and 2-HL networks) using the training algorithms and results' comparison. Secondly is the basic training phase, which focused on training the best group of architecture and algorithm. Based on the initial training results, the network architecture and algorithm combination produced the best results for high level water trip for power plant unit using $(1 \mathrm{HL})$ and $(2 \mathrm{HL})$. The suitable network architecture/algorithm is shown in Table 2 and 3. Figure 1 shows the pure intelligent system result's outputs classified under "boiler drum level low" trip. The total data sampling interval is at the 334th minute before the shutdown instance. The fault was introduced in the 17th interval. The proposed intelligent system detected the fault at 10-minute intervals with an NN output value 0.65. The IMS-I output drops below 0.5 (normal boiler operation) five minutes after the occurrence of the fault and stays in that region for several more intervals. The optimization uses RMSE as a system performance indicator, and specialized IMS code. 
Table 2. The Structure (1HL) for Power Plant High Level Trip Using BFGS QuASI-Newton Back Propagation Training Algorithm

\begin{tabular}{|c|c|c|c|c|c|c|c|c|c|}
\hline & \multicolumn{10}{|c|}{ BFGS Quasi Newton } \\
\hline 1HLN & $\mathbf{L}+\mathbf{L}$ & $\mathbf{L}+\mathbf{T}$ & $\mathbf{L}+\mathbf{P}$ & $\mathbf{T}+\mathbf{T}$ & $\mathbf{T}+\mathbf{L}$ & $\mathbf{T}+\mathbf{P}$ & $\mathbf{P}+\mathbf{P}$ & $\mathbf{P}+\mathbf{L}$ & $\mathbf{P}+\mathbf{T}$ \\
\hline $\mathbf{1}$ & 0.184 & 0.368 & 0.468 & 0.492 & 0.368 & $\mathbf{0 . 1 5 4}$ & 0.486 & 0.361 & 0.395 \\
\hline $\mathbf{2}$ & 0.684 & 0.174 & 0.490 & 0.478 & 0.491 & 0.486 & 0.352 & 0.361 & 0.261 \\
\hline $\mathbf{3}$ & 0.406 & 0.476 & 0.458 & 0.781 & 0.455 & 0.614 & 0.285 & 0.361 & 0.322 \\
\hline $\mathbf{4}$ & 0.610 & 0.693 & 0.616 & 0.249 & 0.775 & 0.674 & 0.372 & 0.232 & 0.358 \\
\hline $\mathbf{5}$ & 0.505 & 0.700 & 0.435 & 0.488 & 0.587 & 0.520 & 0.340 & 0.361 & 0.932 \\
\hline $\mathbf{6}$ & 0.361 & 0.741 & 0.504 & 0.619 & 0.562 & 0.249 & 0.312 & 0.361 & 0.437 \\
\hline $\mathbf{7}$ & 0.573 & 0.572 & 0.468 & 0.561 & 0.459 & 1.000 & 0.304 & 0.259 & 0.932 \\
\hline $\mathbf{8}$ & 0.612 & 0.774 & 0.580 & 0.659 & 0.406 & 0.523 & 0.346 & 0.361 & 0.932 \\
\hline $\mathbf{9}$ & 0.578 & 0.562 & 0.727 & 0.611 & 0.778 & 0.429 & 0.337 & 0.245 & 0.344 \\
\hline $\mathbf{1 0}$ & 0.449 & 0.574 & 0.412 & 0.640 & 0.515 & 1.000 & 0.318 & 0.224 & 0.429 \\
\hline
\end{tabular}

Table 3. The Structure (2HL) For for Power Plant High Level Trip Using BFGS QuASI-Newton BackPropagation Training Algorithm

\begin{tabular}{|c|c|c|c|c|c|c|c|c|c|c|}
\hline $\mathbf{P}+\mathbf{T}+\mathbf{L}$ & \multicolumn{10}{|c|}{ BFGS Quasi Newton } \\
\hline N1 & 1 & 2 & 3 & 4 & 5 & 6 & 7 & 8 & 9 & 10 \\
\hline 1 & 0.244 & 0.570 & 0.368 & 0.368 & 0.529 & 0.808 & 0.368 & 0.368 & 0.368 & 0.368 \\
\hline 2 & 0.368 & 0.361 & 0.118 & 0.163 & 0.449 & 0.249 & 0.737 & 0.533 & 0.368 & 0.510 \\
\hline 3 & 0.368 & 0.368 & 0.361 & 0.422 & 0.361 & 0.564 & 0.789 & 0.544 & 0.454 & 0.579 \\
\hline 4 & 0.267 & 0.522 & 0.692 & 0.932 & 0.644 & 0.626 & 0.694 & 0.512 & 0.395 & 0.932 \\
\hline 5 & 0.368 & 0.251 & 0.625 & 0.368 & 0.819 & 0.493 & 0.457 & 0.534 & 0.237 & 0.815 \\
\hline 6 & 0.577 & 0.361 & 0.463 & 0.368 & 0.425 & 0.721 & 0.664 & 0.376 & 0.685 & 0.722 \\
\hline 7 & 0.368 & 0.906 & 0.236 & 0.562 & 0.566 & 0.631 & 0.611 & 0.515 & 0.365 & 0.490 \\
\hline 8 & 0.291 & 0.472 & 0.346 & 0.473 & 0.516 & 0.162 & 0.725 & 0.624 & 0.275 & 0.581 \\
\hline 9 & 0.368 & 0.270 & 0.296 & 0.605 & 0.374 & 0.430 & 0.789 & 0.742 & 0.388 & 0.907 \\
\hline 10 & 0.368 & 0.623 & 0.571 & 0.368 & 0.374 & 0.410 & 0.606 & 0.598 & 0.463 & 0.573 \\
\hline
\end{tabular}

N1: Neurons's Number In First Hidden Layer; N2: Neurons's Number in Second Hidden Layer L: Logistic, P: Purlin, T: Tangent

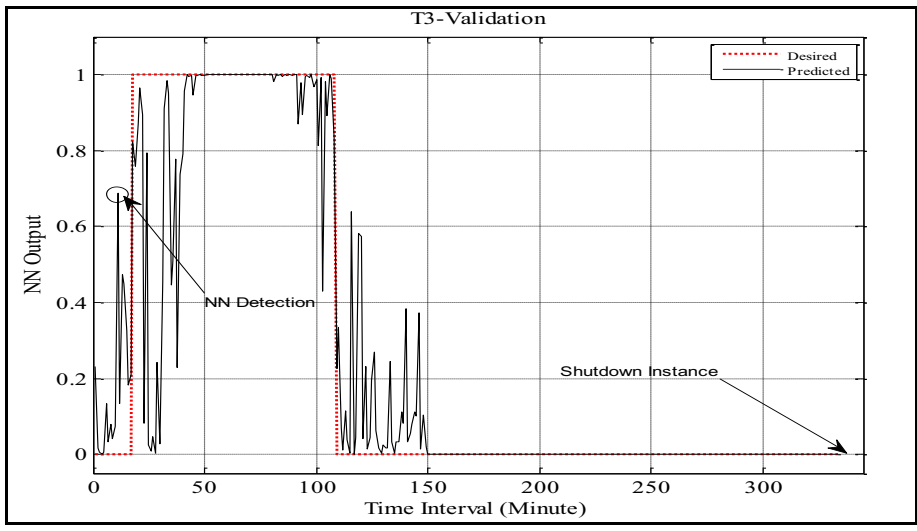

Figure 1. Intelligent System Outputs for High Water Lever Boiler Drum Trip 


\section{Conclusions}

An intelligent monitoring system has been coded and trained using real time plant data. The data it is obtained from a thermal power plant. After multi stages of treatment and classification, the plant data has been adopted to train and validate the ANN code. Furthermore, in the chosen procedure a (1HL) and (2HL) cases have been tested and compared. Four multidimensional training algorithms have been adopted in each case. In conclusion, we have achieved the best optimum NN structure based on the lowest RMSE in the two hidden layers. The training of the neurons were completed by using Broyden-Fletcher-Goldfarb (BFG) quasi-Newton training algorithm.

\section{References}

1. D. Flynn, Thermal Power Plant Simulation and Control. Inst of Eng. \& Tech., (2003).

2. R. E. Uhrig and L. H. Tsoukalas, "Soft computing technologies in nuclear engineering applications," Prog. Nuclear Energy, vol. 34, pp. 13-75, (1999).

3. K. Kim, T. Aljundi and E. Bartlett, Nuclear Power Plant Fault-Diagnosis using Artificial Neural Networks, (1992).

4. G. Guglielmi, T. Parisini and G. Rossi, "Keynote paper: Fault diagnosis and neural networks: A power plant application," Control Eng. Pract., vol. 3, pp. 601-620, (1995).

5. S. Simani and C. Fantuzzi, "Fault diagnosis in power plant using neural networks," Inf. Sci., vol. 127, pp. 125-136, (2000).

6. A. Babar and H. Kushwaha, "Symptom based diagnostic system for nuclear power plant operations using artificial neural networks," Reliability Engineering and System Safety, vol. 82, pp. 33-40, (2003).

7. H. Bae, S. P. Chun and S. Kim, "Predictive fault detection and diagnosis of nuclear power plant using the two-step neural network models," Advances in Neural Networks-ISNN 2006, pp. 420425, (2006).

8. L. M. Romeo and R. Gareta, "Neural network for evaluating boiler behavior," Appl. Therm. Eng., vol. 26, pp. 1530-1536, (2006).

9. H. Rusinowski and W. Stanek, "Neural modelling of steam boilers," Energy Conversion and Management, vol. 48, pp. 2802-2809, (2007). 